\title{
Conference Report: \\ Creating Cities: Culture, Space, and Sustainability (Japan Center, LMU Munich, 27-29 February 2010)
}

\author{
Evelyn Schulz \\ LMU Munich, Germany
}

Organized by: Evelyn Schulz (Japan Center, LMU Munich) in cooperation with Eveline Duerr (Institute for Cultural and Social Anthropology, LMU Munich), Irene Goetz (Institute for European Ethnology, LMU Munich), Franz Waldenberger (Japan Center, LMU Munich), Gordon Winder (Seminar of Economic History, LMU Munich), and the Urban Research Plaza of Osaka City University

Sponsored by: Osaka City University, Japan Foundation, State Ministry for Social Affairs of Bavaria, Equal Opportunities Officer of LMU Munich, Muenchener Universitaetsgesellschaft

Creating Cities: Culture, Space, and Sustainability was an international conference held at the Japan Center, LMU Munich, 27-29 February 2010, that approached the multifaceted and rather controversial creative city debate from different points of view. The conference's goal was to analyze the economic, social, political, and cultural requirements for urban development as well as the global dimension of such processes.

The term creative city is commonly associated with Charles Landry (The Creative City: A Toolkit for Urban Innovators, 2000 and The Art of City Making, 2006) and Richard Florida (The Rise of the Creative Class, 2002; Cities and the Creative Class, 2005; and The Flight of the Creative Class, 2005). According to their theories, those branches of economy that rely on artistic-cultural ideas and the resulting products will play an increasingly important role for the economic and social revitalization of transformed, post-industrial urban regions. The deeper the structural changes and accompanying problems are that a city faces, the more important its so-called creative industries become, according to Landry and Florida. They see the recent international financial meltdown as an important contributor to the acceleration of exactly those changes for the worse that creative industries may help to fight.

The term is also used in connection with the rapidly growing, global Creative Cities Network, a UNESCO initiative. At times, one can hardly help but wonder though, if this isn't just a wellpackaged attempt at city marketing rather than anything else.

As diverse as the international debate on the concept or, rather, the concepts, of a creative city is, there is one common element. Creativity, broadly defined, is seen as a key element for urban

Evelyn Schulz is a Professor at the Japan Center, LMU Munich, Germany. E-mail: evelyn.schulz@lmu.de.

Culture and Local Governance / Culture et gouvernance locale, vol. 3, no. 1-2, 2011. ISSN 1911-7469

(C) Centre on Governance, University of Ottawa, 55 Laurier Avenue East, Ottawa, Ontario, Canada K1N 6N5 
development. Since a pluralistic society is a prerequisite of creativity, the hopes are high that creative industries can facilitate social integration, as can be seen by the Urban Research Plaza of Osaka City University's focus on 'Reinventing the City for Cultural Creativity and Social Inclusion'.

The term creativity seems to bridge a conceptual gap that is the result of challenges posed by today's demand for sustainable urban development strategies. Accordingly, the point of this conference was not so much to examine individual urban creative industries projects. Considering the many different urban development issues, such as shrinking resources, (in)stability, and rampant urban growth, the conference, rather, attempted to shed light on the heterogeneous forces at work and tried to forecast possible future developments.

The conference focused on the following questions: As far as urban development is concerned, how do growth, on one hand, and the necessity for social and ecological sustainability, on the other hand, interact? How does a created environment affect social space? How should a city be in order to promote creativity? When it comes right down to it, what actually is creativity? How do cities approach social and cultural diversity? How do their strategies influence creative activity? Do these kinds of strategies mean a risk too or are they rather the engine behind an economically and socially sustainable urban development? How far can political forces really create a creative city, an urban environment that encourages innovation and economic growth?

These and similar questions were the subject of 18 presentations, divided into five sessions. A wide range of case studies from all over the world and pertaining to a diverse range of fields of study were discussed.

During the first session, titled Creating Cities \& Creative Cities, two case studies from Southeast Asia served to demonstrate how severe disparities can be, especially in terms of urban development, even between neighbouring, de facto interconnected regions. Henry Yeung (Singapore, economic geographer) emphasized Singapore's unique position as a global city-state. According to him, Singapore's steady rise relies heavily on its growing involvement in transnational processes and global production networks. H. Detlef Kammeier (Bangkok, urban planning expert) focused his presentation on urban development projects in small to medium-sized cities in the Mekong-Delta. In his opinion, this is a region of strong growth that is well integrated into global processes despite its apparent remoteness; this is a factor that needs to be taken into account when it comes to urban development. Kammeier closed his presentation by posting a question: Can urban development policies truly be a counterweight to the forces of the global economy?

During the second session, titled Creative Diversity, Socioscapes, and Cultural Politics, Mari Kobayashi (Tokyo, political scientist) analyzed Japan's more recent cultural policies that saw massive spending on the establishment of museums and theatres in provincial regions. Her underlying question was whether the money spent actually led to an increase of creative activity. According to Kobayashi, a constantly increasing amount of money is used for the administration and maintenance of the newly erected buildings while the real budget for cultural activities is dwindling. The sole positive result, according to her, is a noticeable increase in participation in cultural activities by normal citizens. Lidewij Tummers' (Delft, architect) presentation, 'Creative Citizens Meet Creative City Policies', focused on the problems that may arise, as for example in the case of Rotterdam, when a city's politicians intend to support a creative community but fail to 
properly address the concerns of those that make up the creative community to begin with. Evelyn Schulz (Munich, Japanese Studies expert) presented her research findings concerning the ongoing debates on the revaluation and revitalization of small-scale Japanese urban structures, in a presentation titled 'Revitalizing Tokyo's Back Alleys as Areas of Cultural Sustainability and Decelerated Lifestyle'. According to her, during the last century, these back alleys have often been seen as not modern and not economically viable and, therefore, have been destroyed. Recently though, Schulz explained, there has been a renaissance of the traditional small-scale urban space in Japan; some even see it as a possible sustainable model for the future. According to Ana Rosas Mantecón (Mexico, ethnologist), Mexico City used to be a city of social inclusion with a strong modern urban culture throughout the twentieth century. Nowadays though, she claimed, it has become a disorderly megacity with grave social and economic problems. Rosas Mantecón introduced a number of social and cultural projects aimed at revitalizing the city's center and at providing its inhabitants with a positive outlook for the city.

The third session, titled Networks, was concerned with different kinds of networks linked to urban development processes. According to Masayuki Sasaki (Osaka, urban researcher), the recent international financial collapse was just one indicator that the city of the future cannot be a megacity but instead must be comparatively small. He used the case study of Kanazawa, a city of approximately 450,000 inhabitants that is part of the UNESCO Creative Cities Network, to illustrate how social inclusion can be achieved through the support and development of local creative industries. Gordon Winder's (Munich, economic and historical geographer) presentation, titled 'Mediating a Global Network in Crisis: The New York Times Maps the Moral Geography of Global Finance', took a closer look at the vocabulary employed by The New York Times to chart the recent financial meltdown. In the presentation, he delineated the noticeably U.S.-centric, imagined networks that the paper saw New York to be a part of during the period 12-28 February 2009. Ute Lehrer (Toronto, architect and urban planning expert) concerned herself with Toronto's condominium tower boom. As she explained, this kind of building is specifically geared towards an affluent clientele who desire high-end living spaces. Lehrer called these condominium towers vertically networked suburbs as each of them offers a comprehensive infrastructure that resists being integrated into the, generally speaking, less privileged surroundings. Paul Waley (Leeds, geographer) used his presentation, 'Picking a Path through Networks of Urban Theories towards Theories of Urban Networks: Japanese and Chinese Cities Within an East Asian Regional Urbanism', to call for urban development approaches in China and Japan specifically tailored to the needs of cities there rather than simply analyzing East Asian problems in terms of Euro-centric theories.

During the fourth session, titled Mobility and Built Environment, Glen Norcliffe (Toronto, economic geographer) concerned himself with the possible advantages of tricycles as a means of transportation in the near future in urban settings in China, South and Southeast Asia, and South America. According to him, the two main factors to be considered in this context are the desire for a hypermobile lifestyle, on one hand, and for a sustainable environment on the other. Manabu Noda (Tokyo, performing arts expert) laid out how Shibuya became one out of three main sub-centers of Tokyo, starting in the 1920s. He explained how Shibuya became an immensely popular center of consumerism and entertainment among young Japanese during the 1980s and 1990s. Citing two 
2004 plays as examples, Noda outlined his perception of what could be called Shibuya's descent. To him, the current Shibuya has become a gathering place for a youth without proper roots, without a home. Sonja Beeck (Dessau, architect) shared her experience from case studies from the former German Democratic Republic in a presentation titled 'Paradigm Shift: From Growth to Quality'. According to her, whenever there are shrinking processes at work, there are also urban planning opportunities. In her opinion, a master plan can not be employed under these circumstances, as it would be based on the presumption of growth by its very nature. Beeck instead sees great potential in small-scale solutions, based on citizens' input. Roger Keil's (Toronto, political scientist and urban researcher) presentation was based on Thomas Sieverts' idea of the Zwischenstadt or in-betweencity. Keil utilized Sieverts' theory to demonstrate how, in his opinion, Toronto's suburban space is, in general, neglected as far as urban planning is concerned and has, therefore, become unattractive and featureless. He pointed out, though, that many elements of global entertainment culture can be seen to actually originate from just these kind of in-between-cities.

The fifth and final session was concerned with different aspects of City Marketing. Hiroshi Okano (Osaka, economist) talked about the development of control mechanisms as a part of successful marketing strategies as well as possible ways by which the success of marketing strategies can be measured. Brett Christophers (Uppsala, geographer) presented the case study of Croydon in south London. According to him, this location's initially rather low appeal was greatly improved by marketing and image campaigns, although the purpose was to buy out the landowners and construct prestigious large-scale projects. Nicolas Lewis' (Auckland, economic geographer) presentation, 'Branding Auckland: Creating Creativity and Suspending Disbelief', introduced three initiatives aimed at positioning Auckland as its own international tourism and economic brand. The question he posed concerned how far these undertakings were really aimed at supporting the local creative economy and how far they were mere marketing strategies to promote consumerism. Klaus R. Kunzmann (Potsdam, spatial planning expert) presented a quite critical view on what he called creative city fever, an international phenomenon, according to him, with doubtful staying power. In Kunzmann's opinion, the only reasonable explanation for the popularity of the theory of creative cities so far is the lack of a clear definition of what the concept actually entails. According to him, the economic potential of creative cities is generally overestimated and it would be wise to look into the creativity of and in cities instead.

The last presentation led to a lively closing debate. Strengths and weaknesses of the concept were discussed. In general, metropolitan cities with a rich cultural heritage seem to be the winners in the creative city paradigm. While it can hardly be denied that, even there, much of the allocated money is spent in order to create the illusion of innovation (for example, by means of flagship projects and events on a grand scale) it can nonetheless be observed that the local creative and cultural industries and their related institutions profit as well. New approaches to urban development have been advanced in order to increase the quality of life in targeted areas and to conserve local cultural traditions while strengthening cultural education. On the other hand, gentrification and social polarization can also be linked to the very same creative policies, which usually refuse to include the working class and immigrants altogether. It is the small- and mediumsized cities that were seen as the real losers of the creative city paradigm. More often than not, their only hope, it seems, is to tap into the economic and social benefits of an adjacent creative capital. 


\section{References}

Landry, C. (2000). The creative city: A toolkit for urban innovators. London: Earthscan.

Landry, C. (2006). The art of city making. London: Earthscan.

Florida, R. (2002). The rise of the creative class: And how it's transforming work, leisure, community and everyday life. New York: Perseus Book Group.

Florida, R. (2005). Cities and the creative class. New York: Routledge.

Florida, R. (2005). The flight of the creative class: The new global competition for talent. New York: HarperCollins. 